ノート・ Note

\title{
Grain Orientation and Electrical Properties of Hot-Pressed Bismuth Titanate Ceramics
}

\author{
Yoshiki INOUE, Toshio KIMURA, Takashi YAMAGUCHI, \\ Kunihiro NAGATA* and Kiyoshi OKAZAKI* \\ Faculty of Science and Technology, Keio University \\ 3-14-1, Hiyoshi, Kohoku-ku, Yokohama-shi 223 \\ * Department of Electrical Engineering, The National Defence Academy
}

[Received December 15, 1983]

\section{ホットプレスしたチタン酸ビスマスセラミックスの 粒子配向と電気的性質}

\author{
井上芳樹 ·木村敏夫 ·山口喬 - 永田邦裕* ·岡崎 清* \\ ( 慶応大学 理工学部 応用化学科) \\ * 防衛大学校 電気工学教室
}

(1983 年 12 月 15 日受付)

Key-words : $\mathrm{Bi}_{4} \mathrm{Ti}_{3} \mathrm{O}_{12}$, Hot-press, Grain orientation

\section{Introduction}

Hot-pressing is one of the important preparation methods of grain-oriented ferroelectric and piezoelectric ceramics ${ }^{1}$. The effects of processing parameters on the grain orientation, however, are not fully understood. This paper deals with the effect of the particle shape of starting powders on the grain orientation. Lumpy and plate-like $\mathrm{Bi}_{4} \mathrm{Ti}_{3} \mathrm{O}_{12}$ powders with controlled particle morphology were prepared by solid state method and molten salt synthesis ${ }^{2}$, respectively. The degree of orientation was estimated by X-ray diffraction and dielectric constant. Piezoelectric property was measured also.

\section{Experiments}

The preparation method of starting powders are described elsewhere ${ }^{2,3)}$. Briefly, stoichiometric mixtures of $\mathrm{Bi}_{2} \mathrm{O}_{3}$ and $\mathrm{TiO}_{2}$ were heated with mixed sulfates $(\mathrm{S})$ or chlorides $(\mathrm{C})$ or without salt $(\mathrm{N}) . \mathrm{Bi}_{4} \mathrm{Ti}_{3} \mathrm{O}_{12}$ powders so obtained will be called by the abbreviated form of the salts used and preparation temperature (Table 1). Figure 1 shows the scanning electron microscope (SEM) photographs of the obtained $\mathrm{Bi}_{4} \mathrm{Ti}_{3} \mathrm{O}_{12}$ powders. The particle size and aspect ratio (plate diameter/thickness) of the plate-like particles increased with increasing preparation temperature. The aspect ratio of powder $\mathrm{C}$ was larger than that of powder $\mathrm{S}$, as compared at the same preparation temperature.

The powders were pressed uniaxially into pellets 15 $\mathrm{mm}$ in diameter and $20 \mathrm{~mm}$ in height under a pressure of $1000 \mathrm{~kg} / \mathrm{cm}^{2}$. The green compact was placed in an alumina die with $\mathrm{ZrO}_{2}$ compaction powder and heated up to $800^{\circ} \mathrm{C}$ in vacuum and then to $1050^{\circ} \mathrm{C}$ in oxygen at the heating rate of $300^{\circ} \mathrm{C} / \mathrm{h}$. After the temperature reached $1050^{\circ} \mathrm{C}$, the pressure of $200 \mathrm{~kg} / \mathrm{cm}^{2}$ was applied. After 5 $\mathrm{h}$ at $1050^{\circ} \mathrm{C}$ under pressure, the pressure was removed and the sample was cooled in the furnace. Ordinarily sintered pellet was also prepared under the same conditions without applied pressure. The sintered materials were cut into thin wafers in two directions as

Table 1. Preparation conditions of starting powders.

\begin{tabular}{l|l|rc}
\hline Sample & Flux & $\begin{array}{c}\text { Temp. } \\
\left({ }^{\circ} \mathrm{C}\right)\end{array}$ & $\begin{array}{c}\text { Time } \\
(\mathrm{h})\end{array}$ \\
\hline N800 & & 800 & 2 \\
S800 & Sulfates & 800 & 6 \\
S1050 & Sulfates & 1050 & 1 \\
C800 & Chlorides & 800 & 6 \\
C1050 & Chlorides & 1050 & 1 \\
\hline
\end{tabular}



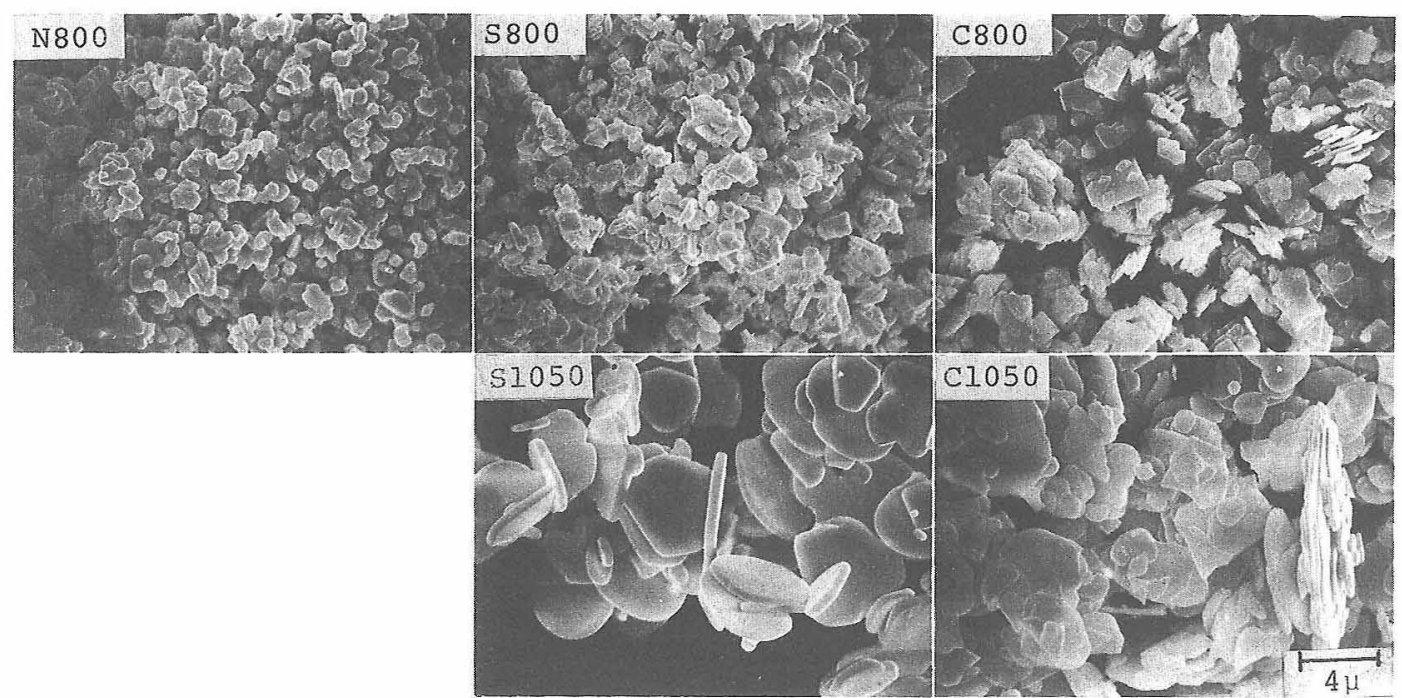

Fig. 1. Scanning electron microscope photographs of the starting powders.

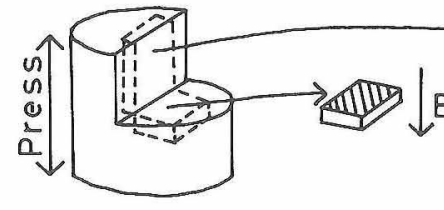

(II)

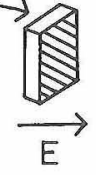

( 1$)$

\section{Electrode E: Electric field}

Fig. 2. Preparation of wafers.

shown in Fig. 2. The cutting directions are represented based on the directional relation between the applied pressure and electric field.

The microstructural characteristics were determined on the wafer surfaces; the degree of orientation by X-ray diffraction analysis ${ }^{31}$ and SEM observation on thermally etched surfaces. Gold electrodes were sputtered on the major surfaces and electrical properties such as temperature dependence of dielectric constant at 10 $\mathrm{MHz}$, voltage-current characteristics at $150^{\circ} \mathrm{C}$ and electro-mechanical coupling factor $k_{\mathrm{t}}$ were determined by an impedance analyser.

\section{Results and discussion}

Figure 3 illustrates the X-ray diffraction profiles of the parallel wafers of hot-pressed and ordinarily fired S 1050 and N 800 powders with their measured faces perpendicular to the pressing direction. The intensity of (001) diffraction line increased by hot-pressing. Table 2 shows the degree of orientation. The degree of orientation of the ordinarily fired $\mathrm{N} 800$ was 0 but that of plate-like powders was between 0.15 and 0.32 ,

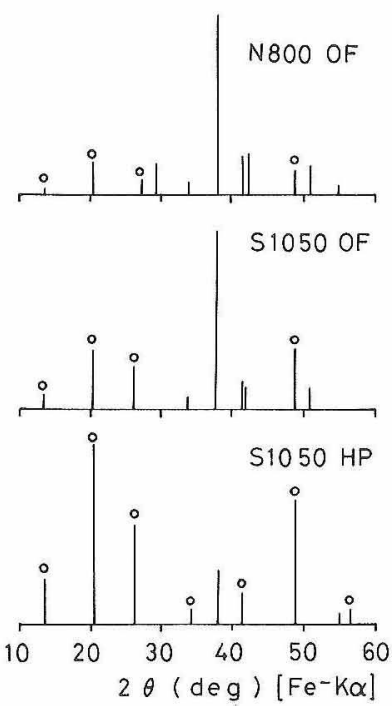

Fig. 3. X-ray diffraction patterns of hot-pressed (HP) and ordinarily fired (OF) N 800 and S 1050. Circle indicates that the line belongs to $(00 \mathrm{l})$.

Table 2. Density and degree of orientation of hotpressed ( $\mathrm{HP}$ ) and ordinarily fired (OF) wafers.

\begin{tabular}{|c|c|c|c|c|c|}
\hline \multirow[t]{2}{*}{ Powder } & \multicolumn{2}{|c|}{ Density $(8)$} & $\begin{array}{r}\text { Degre } \\
\mathrm{x}-\end{array}$ & $\begin{array}{l}\text { of or } \\
\text { ay }\end{array}$ & $\begin{array}{l}\varepsilon_{\perp} / \varepsilon_{/ \prime} \\
\text { ention }\end{array}$ \\
\hline & HP & OF & HP & OF & $\mathrm{HP}$ \\
\hline N800 & 99.9 & 94.4 & 0.87 & 0.00 & 4.1 \\
\hline 5800 & 99.9 & 94.1 & 0.82 & 0.15 & 3.3 \\
\hline S1050 & 100.0 & 94.8 & 0.76 & 0.20 & 2.9 \\
\hline $\mathrm{C} 800$ & 99.9 & 89.8 & 0.77 & 0.22 & 3.3 \\
\hline C1.050 & 99.9 & 88.9 & 0.82 & 0.32 & 3.6 \\
\hline
\end{tabular}

indicating that the orientation was achieved to some extent in the green compacts of the plate-like powders. The hot-pressed waler of $\mathrm{N} 800$, on the other 


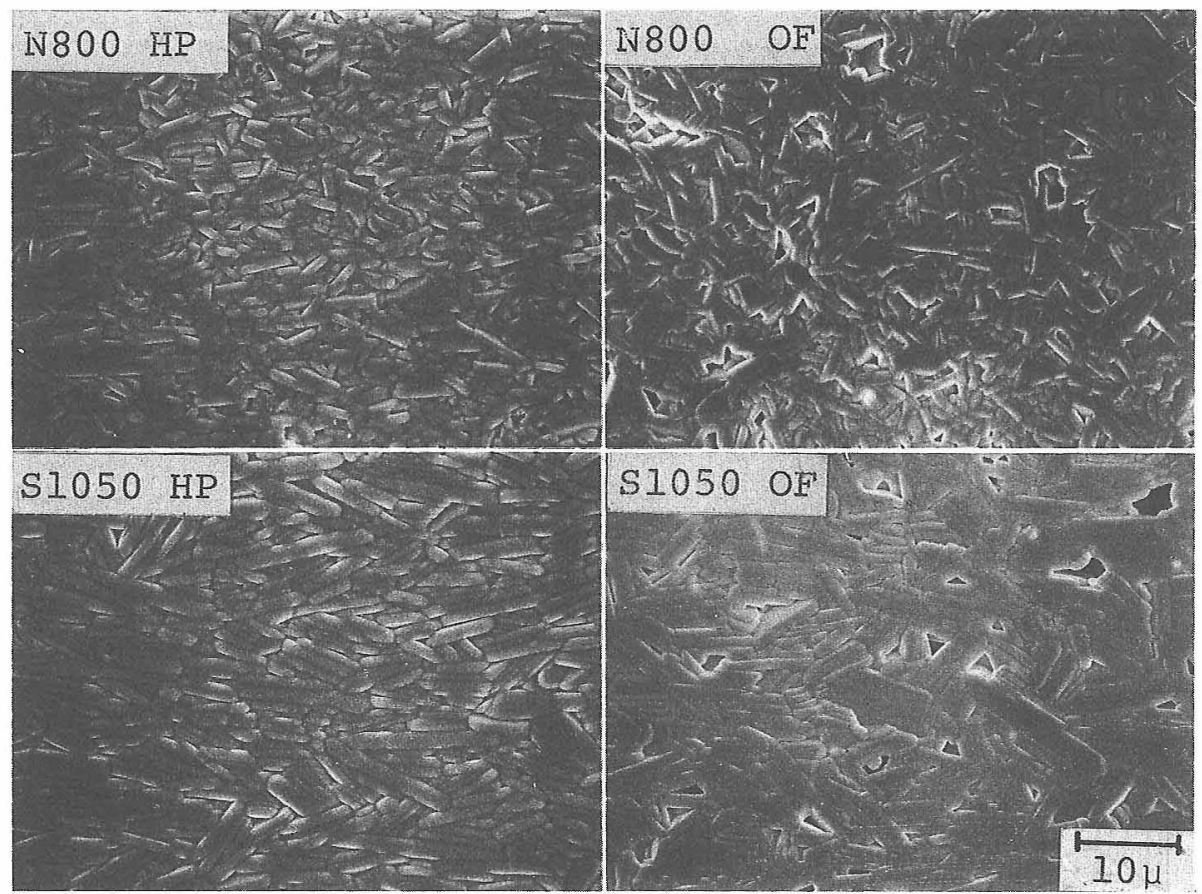

Fig. 4. Scanning electron microscope photographs of hot-pressed (HP) and ordinarily fired (OF) N 800 and S 1050 (the faces are parallel to the pressing direction).

hand, had the largest degree of orientation. Figure 4 shows the SEM photographs of hot-pressed and ordinarily fired S 1050 and N 800 powders. As compared with Fig. 1, grain growth was evident and hot-pressing had no effect on the grain size. One of the microstructural characteristics of the ordinarily fired wafers was the large pores between the grains. No pores were observed in the hot-pressed specimens (densities are shown in Table 2). The plate-like grains have grown perpendicular to the hot-pressing direction.

Figure 5 illustrates the temperature dependence of dielectric constant of hot-pressed and ordinarily fired S 1050. Dielectric constant of the hot-pressed sample was highly anisotropic, especially near Curie temperature. The ratio of dielectric constants $\varepsilon_{\perp} / \varepsilon_{/ /}$ at Curie temperature could be used as a measure of grain orientation and agreed well with that obtained by X-ray diffraction analysis (Table 2 ).

The fact that the hot-pressed N 800 had the largest degree of orientation might be explained as follows. The rate of grain growth of $\mathrm{Bi}_{4} \mathrm{Ti}_{3} \mathrm{O}_{12}$ is larger along $a$ axis than along $c$ axis (crystal structure is tetragonal at $1050^{\circ} \mathrm{C}$ ). In ordinarily fired $\mathrm{N} 800$ the grains grow into plate-like shape (Fig.4), but their orientation is

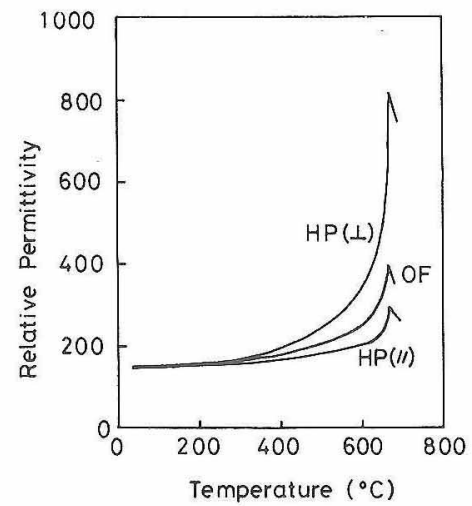

Fig. 5. Temperature dependence of dielectric constant of hot-pressed (HP) and ordinarily fired (OF) S 1050.

random, because every particle has a possibility of growth. In hot-pressed $\mathrm{N} 800$, on the other hand, the uniaxial pressure would influence the rate of grain growth along the crystallographic axes. Thus, the particles having $c$ axis parallel to the pressing direction have a larger possibility of growth and grow at the expense of other particles oriented in other directions, resulting in highly oriented plate-like grains. In the green compacts of plate-like powders, the particles were aligned to some extent, as judged 


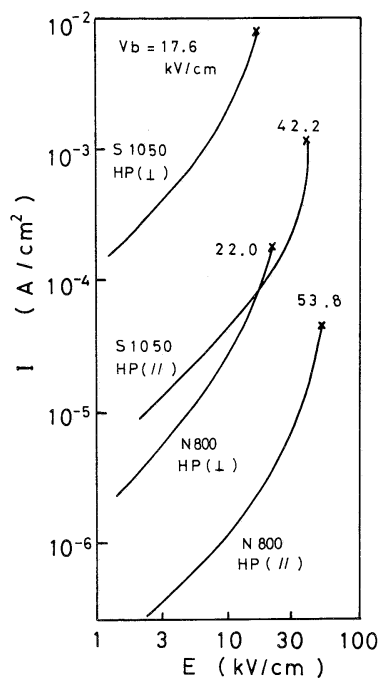

Fig. 6. Current-voltage characteristics of hot-pressed N 800 and $\mathrm{S} 1050\left(V_{\mathrm{b}}\right.$ : Breakdown voltage).

from the degree of orientation in the ordinarily fired samples. The difference in growth rates between partially oriented particles would be smaller than that between randomly oriented particles, resulting in the growth of slightly misoriented grains and smaller degree of orientation. The degree of orientation of the ordinarily fired plate-like powders indicates that the larger degree of particle alignment in the green compact results in the larger grain orientation in the hot-pressed wafers except for S800. In S 800 the degree of particle alignment is small and the sintering behavior would be close to a randomly packed compact.

Figure 6 illustrates the voltage-current characteristics of the hot-pressed S 1050 and N 800. In both specimens the parallel wafers had a larger electrical
Table 3. Electro-mechanical coupling factor of hot-pressed (HP) and ordinarily fired (OF) N 800 and S 1050.

\begin{tabular}{l|cc|c}
\hline Sample & \multicolumn{3}{|c|}{ Coupling Factor $\mathrm{k}_{\mathrm{t}}$} \\
& \multicolumn{1}{|c|}{$\mathrm{HP}$} & $\mathrm{OF}$ \\
& $\perp$ & $/ /$ & \\
\hline $\mathrm{N} 800$ & 0.23 & 0.07 & 0.17 \\
S1050 & 0.28 & 0.09 & 0.15 \\
\hline
\end{tabular}

resistivity and breakdown voltage than those of perpendicular wafers. The wafers of N 800 had a larger resistivity than those of S 1050. Probably the residual sulfates used in the powder preparation reduced the resistivity.

The electro-mechanical coupling factor $k_{\mathrm{t}}$ was measured after poling at 30 and $15 \mathrm{kV} / \mathrm{cm}$ at $150^{\circ} \mathrm{C}$ for parallel and perpendicular wafers, respectively. The frequency-impedance characteristics of the wafers were measured and $k_{\mathrm{t}}$ was calculated from the frequencies of the maximum and minimum peaks. Table 3 shows $k_{\mathrm{t}}$ values of hot-pressed and ordinarily fired S 1050 and $\mathrm{N} 800$. Anisotropy in $k_{\mathrm{t}}$ was obvious in the hotpressed samples. A larger anisotropy could be expected from the spontaneous polarization $\left(50 \times 10^{-2}\right.$ and $4 \times 10^{-2} \mathrm{C} / \mathrm{m}^{2}$ along $a$ and $c$ axes at room temperature $\left.{ }^{4}\right)$. The smaller poling voltage due to the smaller breakdown voltage in the perpendicular wafers would be responsible for the smaller anisotropy than expected.

\section{References}

1) H. Igarashi and K. Nagata, Bull. Ceram. Soc. Japan, 18, 198-204 (1983).

2) T. Kimura and T. Yamaguchi, Ceramics International, 9, 13-17 (1983).

3) Y. Inoue, T. Kimura and T. Yamaguchi, Am. Ceram. Soc. Bull., 62, 704-09, 711 (1983).

4) S.E. Cummins and L.E. Cross, J. Appl. Phys., 39, 2268-74 (1968). 